\title{
ه Receptor-mediated exopolysaccharide ص perception controls bacterial infection
}

3 Y. Kawaharada, ${ }^{1,2}$, S. Kelly ${ }^{1,2,3}$, M. Wibroe Nielsen ${ }^{1,2}$, C. T. Hjuler, ${ }^{1,4}$, K. Gysel $1^{1,2}$, A. Muszyński ${ }^{5}$, R. W. Carlson ${ }^{5}$, M. B. Thygesen ${ }^{1,4}$, N. Sandal $1^{1,4}$, M. H. Asmussen ${ }^{1,2}$, M. Vinther ${ }^{1,2}$, S. U. Andersen ${ }^{1,2}$, L. Krusell ${ }^{1,2}$, S. Thirup ${ }^{1,2}$, K. J. Jensen ${ }^{1,4}$, C. W. Ronson ${ }^{1,3}$, M. Blaise $e^{1,2}$, S. Radutoiu ${ }^{1,2} \uparrow \&$ J. Stougaard ${ }^{1,2}$

\begin{abstract}
Surface polysaccharides are important for bacterial interactions with multicellular organisms, and some are virulence factors in pathogens. In the legume-rhizobium symbiosis, bacterial exopolysaccharides (EPS) are essential for the development of infected root nodules. We have identified a gene in Lotus Japonicus, Epr3, encoding a receptor-like kinase that controls this infection. We show that epr3 mutants are defective in perception of purified EPS, and that EPR3 binds EPS directly and distinguishes compatible and incompatible EPS in bacterial competition studies. Expression of Epr3 in epidermal cells within the susceptible root zone shows that the protein is involved in bacterial entry, while rhizobial and plant mutant studies suggest that Epr3 regulates bacterial passage through the plant's epidermal cell layer. Finally, we show that Epr3 expression is inducible and dependent on host perception of bacterial nodulation (Nod) factors. Plant-bacterial compatibility and bacterial access to legume roots is thus regulated by a two-stage mechanism involving sequential receptor-mediated recognition of Nod factor and EPS signals.
\end{abstract}

Bacteria display a variety of glycans on their surfaces. Capsular polysaccharides, lipopolysaccharides, cyclic glucans and exopolysaccharides (EPS) form an adaptable dynamic interface involved in, for example, cell-to-cell interactions, immune evasion, pathogenesis, biofilm formation and colonization of ecological niches, such as the intestinal lumen and epithelial surfaces ${ }^{1-3}$. In the legume-rhizobium symbiosis, mutational analysis of rhizobia has revealed a role for polysaccharides in the chronic intracellular infection of plant cells of nitrogen-fixing root nodules ${ }^{4-6}$. Legumes inoculated with compatible rhizobia form nodule primordia from new cell divisions in the root cortex in response to Nod factors produced by rhizobia, and simultaneously a bacterial infection process targets these primordia $^{6-8}$. Infection of most legumes, including the model legume Lotus japonicus is initiated when bacteria become entrapped by a curled root hair and divide to form a microcolony. Local cell wall hydrolysis and invagination of the plant plasma membrane then leads to formation of infection threads that are colonized by multiplying bacteria $^{9,10}$. These tubular structures proceed through the epidermal cell layer into the root cortex before ramifying in the underlying nodule primordia. Finally, rhizobia are released into plant cells in an endocytotic process and maintained in membrane-delimited compartments called symbiosomes.

The role of bacterial EPS in this infection process has been most extensively studied in the Sinorhizobium meliloti-alfalfa and Rhizobium leguminosarum-pea symbioses. Mutants of both S. meliloti and R. leguminosarum defective in EPS biosynthesis are severely impaired in their ability to initiate or elongate infection threads ${ }^{11,12}$. An octasaccharide trimer of $S$. meliloti succinoglycan is symbiotically active $^{13}$. However, the composition and structure of EPS produced by rhizobia varies among strains, suggesting specialized functions in host-rhizobial interactions. Variations in both the monosaccharide composition of subunit backbones and in the degree of polymerization have been reported ${ }^{14}$. Exemplifying this variation, some
S. meliloti strains produce both succinoglycan ${ }^{15,16}$ and galactoglucan ${ }^{17}$, whereas R. leguminosarum EPS is a polymer of a decorated octamer containing glucuronic acid ${ }^{18}$. Strain-specific decorations include noncarbohydrate substituents such as O-acetyl, pyruvyl and succinyl groups ${ }^{14}$. Illustrating the importance of these variations, S. meliloti mutants producing EPS lacking the succinyl groups exhibit impaired infection-thread formation ${ }^{12}$.

The precise function of rhizobial EPS and the role of structural variations during infection remain unresolved. An active role in signalling to ameliorate plant defence responses has been proposed ${ }^{19,20}$, as have passive roles, such as prevention of cellulose-mediated agglutination $^{21}$, sequestering of calcium ions ${ }^{22}$, and protection against changeable osmotic conditions or against host-derived reactive oxygen species ${ }^{23}$. We addressed the question of EPS function by asking whether plants directly perceive EPS in a receptor-mediated process controlling legume-rhizobium compatibility. Here we show that legume host plants monitor the structure of EPS secreted by rhizobia at the initiation of infection and we identify a LysM serine/threonine receptor kinase central to this novel non-self detection mechanism.

\section{The EPR3 exopolysaccharide receptor}

Wild-type Mesorhizobium loti strain R7A (R7A) synthesizes and secretes an $\mathrm{O}$-acetylated acidic EPS giving rise to mucoid colony growth $^{24}$. In contrast, R7AexoU mutants of this strain impaired in the exoU glucosyltransferase gene secrete a penta-glycan (truncated EPS; Fig. 1a) and have a rough colony appearance ${ }^{24}$. When inoculated onto wild-type Lotus japonicus plants of ecotype Gifu, R7AexoU induced barely visible uninfected root nodule primordia (Fig. 1c, f) compared to infected mature nodules induced by R7A (ref. 24) (Fig. 1b, e). This distinct phenotype provided a well-defined baseline for a suppressor mutant screen aimed at identifying plant genes involved in the response to bacterial EPS. A suppressor line, exo277, that developed mature nodules was isolated (Fig. 1d), and 


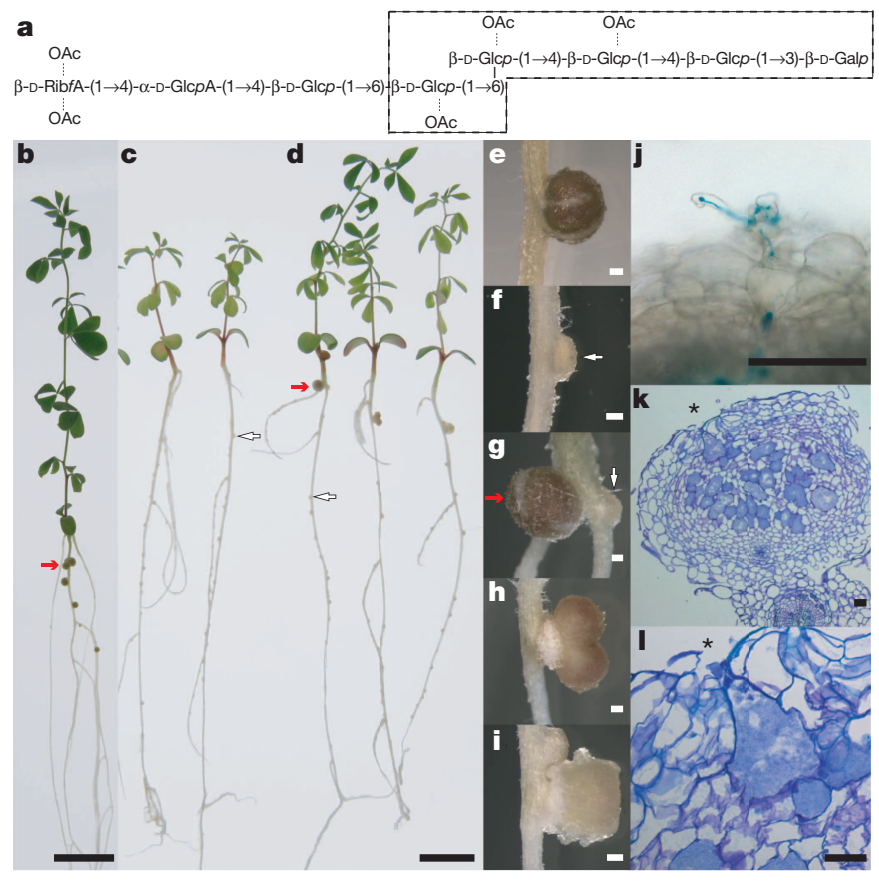

Figure $1 \mid$ Phenotype of epr3 suppressor mutant. a, Proposed structure of monomeric EPS (average of three O-acetyl (OAc) groups per monomer). Dashed lines show R7AexoU truncated EPS. Glcp, glucose; Galp, galactose; RibfA, riburonic acid. b, Representative of R7A-inoculated Gifu. c, Two R7AexoU-inoculated Gifu. d, Three R7AexoU-inoculated exo277/epr3-10. e, Representative R7A-infected Gifu nodule. f, Small white R7AexoU-induced primordium on Gifu. $\mathbf{g}-\mathbf{l}$, R7AexoU-inoculated specimens, representative examples of infected nodules $(\mathbf{g}, \mathbf{h})$ and a large infected white nodule on epr3-10 (i). b-g, Red and white arrows mark infected and uninfected nodules. j, Elongated infection thread of epr3-10. k, Crack entry in epr3-10 nodule. 1, Close up of the infection pocket (indicated by the asterisk). Scale bars: b-d, $1 \mathrm{~cm} ; \mathbf{e}-\mathbf{i}, 20 \mu \mathrm{m} ; \mathbf{j}-\mathbf{l}, 50 \mu \mathrm{m}$. $n$ values relating to representative images are provided in Extended Data Table 1.

subsequent inoculation of progeny plants with R7AexoU constitutively expressing a DsRed reporter gene revealed an intermediate frequency of infected nodules (Extended Data Table 1). Both fully developed pink and large white nodules were formed in approximately equal numbers (Fig. 1g-i). In contrast to the small white 'bumps', these nodules were infected-as detected by DsRed fluorescence. In order to identify the causative gene, the recessive exo277 locus was genetically mapped to a region on chromosome 2 encompassing a LysM receptor-like kinase gene, Lys $3^{25}$ (Extended Data Fig. 1a). Subsequent sequencing of $L y s 3$ from exo277 identified a single-nucleotide mutation (CCC to CTC) that changed Pro to Leu in the LysM3 domain of the corresponding protein (Extended Data Figs $1 \mathrm{~b}$ and 2a). In light of the functional characterization presented below, we renamed Lys3 as Epr3 (exopolysaccharide receptor 3) and the exo277 allele as epr3-10. To substantiate the gene identification a set of TILLING ${ }^{26}$ alleles were phenotyped with the R7AexoU DsRed strain (Supplementary Table 1). Two alleles, epr3-3 and epr3-9, had an intermediate frequency of infected nodules similar to epr3-10 (Extended Data Table 1). A single-nucleotide substitution (TGT to TAT) changed a cysteine in one of the $\mathrm{CxC}$ cysteine pairs of the EPR3 ectodomain to tyrosine in epr3-3 (Extended Data Fig. 2a). In epr3-9 a splice-site mutation (G to A) at the border of exon 8 led to aberrant splicing (Supplementary Table 1). Additional alleles epr3-11, epr3-12 and epr3-13, carrying insertions in exon one, two and three, respectively, were isolated from the LORE1 retrotransposon mutant resource $^{27,28}$ (Extended Data Fig. 1b, Extended Data Table 1 and Supplementary Table 1). Upregulation of Epr3 expression was not detected in epr3-11 (Extended Data Fig. 3a) and epr3-11 was therefore chosen as a presumptive null allele for further phenotypic characterization together with epr3-10.

Epr3 consists of ten exons and encodes a protein of approximately $70 \mathrm{kDa}$. A signal peptide and three LysM motifs are predicted in the amino terminus. The carboxy terminus contains motifs conserved in serine/threonine kinases. Between these domains a single-pass transmembrane segment suggests a topology with LysM motifs in the ectodomain and an intracellular kinase (Fig. 2a and Extended Data Fig. 2b). Supporting this prediction transient expression of an eYFP-tagged EPR3 protein in Nicotiana benthamiana leaves localized the protein at the plasma membrane (Extended Data Fig. 4a-c). Phylogenetically EPR3 belongs to the Nod factor receptor 1 (NFR1) protein branch among the 17-member LysM receptor kinase family of L. japonicus ${ }^{25}$. However, both LysM2 and LysM3 have diverged (Extended Data Fig. 5), and EPR3 is unique in the organization of ectodomain motifs. The $\mathrm{CxC}$ signature adjacent to the LysM domains of all 17 receptors is located immediately after both LysM1 and LysM2 in EPR3 (Fig. 2b and Extended Data Fig. 2a, b). In contrast to the LysM domains of the CERK1 chitin receptor and NFR1, which have characteristic $\beta 1 \alpha 1 \alpha 2 \beta 2$ structures $^{29,30}, \beta 1 \alpha 2 \beta 2$ and $\beta 1 \alpha 1 \beta 2$ configurations are predicted for EPR3 LysM1 and LysM2, respectively. Likewise, motifs involved in the LysM2 chitin-binding site of CERK1 and residues interacting with the $\mathrm{N}$-acetyl of chitin $^{30}$ are not conserved in EPR3, but are discernable in LysM2 of NFR1 (Fig. 2b). LysM receptor kinases with a similar arrangement of $\mathrm{CxC}$ motifs, $\alpha$-helix predictions and conservation of the Pro substituted in LysM3 of EPR3-10 were found in both dicots and monocots (Extended Data Fig. 2a, b).

\section{EPR3 controls infection at the epidermis}

Increased R7AexoU infection of nodule primordia in epr3 mutants suggests a role for truncated EPS and EPR3 in regulation of bacterial

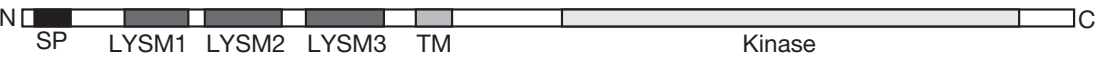

b


2 | NATURE | VOL 000 | 00 MONTH 2015

Nature nature14611.3d 20/6/15 08:17:06
Figure $2 \mid$ Domain structure of EPR3 receptor protein. a, Diagram presenting the EPR 3 domains. SP, signal peptide; TM, transmenbane domain. b, Positions of $\mathrm{CxC}$ di-cysteine motifs (dark grey), $\alpha$-helix (green) and $\beta$-strand (red) predictions for the LysM domains in CERK1, NFR1 and EPR3. Black boxes indicate CERK1 residues interacting with chitin. Asterisks indicate a conserved amino acid; colons indicate a conservative position; periods indicate a semi-conservative position. 
entry across the epidermal cell layer. We therefore recorded the number of infection threads reaching the base of root hair cells at the epidermal-cortical cell boundary (long infection threads; Figs $1 j$ and $3 \mathrm{a}, \mathrm{b}$ ) and/or infection threads not reaching the epidermal-cortical cell boundary (short infection threads; Fig. 3a, c) 10 and 14 days post inoculation (d.p.i.). Inoculation of Gifu with R7AexoU resulted in a five- to tenfold reduction in total infection threads compared to R7A, and at 10 d.p.i. no infection threads reached the base of root hair cells (Fig. 3a). In epr3-10 and epr3-11, infection-thread initiation by R7AexoU was increased and progression was observed (Fig. 3a). At 10 and 14 d.p.i. significantly more long infection threads had reached the cortical boundary in epr3-10, and at 14 d.p.i. the total number of infection threads was significantly higher in both epr3-10 and epr3-11 (Fig. 3a). Further microscopy of R7AexoU-infected nodules on epr3-10 and epr3-11 revealed an alternative infection by crack entry (Fig. 1k, 1). These observations suggested a function for Epr3 in regulation of infection rather than in the nodule organogenic pathway required for cell division and primordia formation. This was further substantiated by the absence of R7AexoU infection in snflharl and snf2harl double mutants that develop an excess of spontaneous nodules as a result of autoactivation of the organogenic pathway $^{31,32}$. Therefore, activation of the host organogenic pathway per se did not rescue the infection deficiency of R7AexoU (Extended Data Table 2a). We conclude that the EPR3 receptor exerts a primary function controlling infection, whether intracellular through infection threads or intercellular via crack entry. In epr3 mutants this control is defective and R7AexoU is able to initiate more infection threads as well as crack entries, even when the positive effect of EPR3 described below is absent (Fig. 3a).

The suppressor phenotype suggested a ligand-receptor relationship between truncated EPS and EPR3. However, the function of wild-type EPS as a ligand for EPR3 was unclear. The consequences of receptor inactivation and the reciprocal absence of a putative EPS ligand in the R7AexoB mutant were therefore compared. ExoB is the UDP-glucose 4-epimerase that synthesizes UDP-glucose required for the first step of EPS synthesis, and R7AexoB does not synthesize EPS.

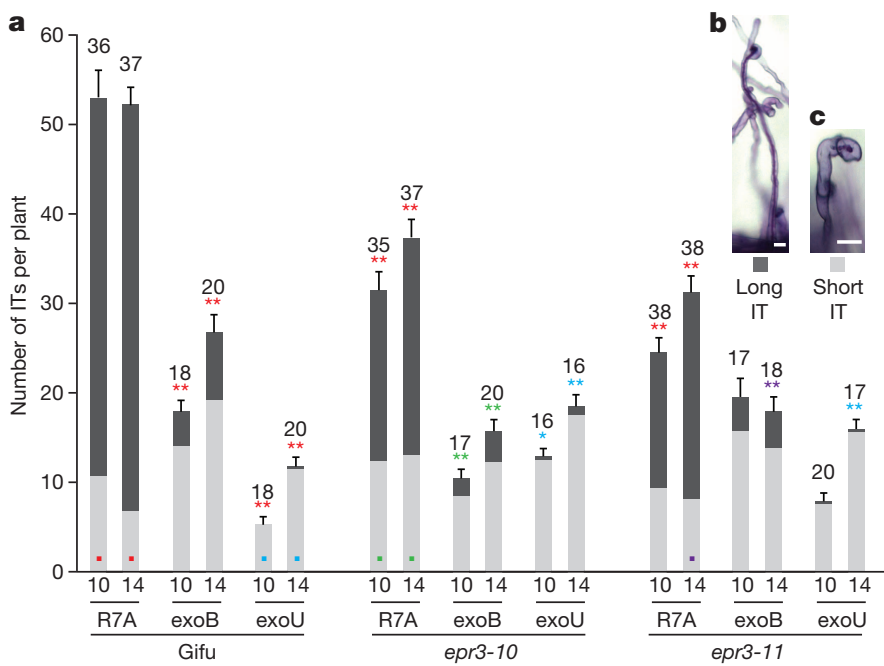

Figure $3 \mid$ EPS perception promotes infection thread development. a, Frequency of infection threads (ITs) after R7A, R7AexoB or R7AexoU inoculation of Gifu, epr3-10 and epr3-11. Summed over ten plants the number of R7AexoU-induced long infection threads at 10 and 14 d.p.i. are: Gifu, 0 and 1.5; epr3-10, 5 and 9.4; epr3-11, 2 and 3.5. ${ }^{* *} P<0.01$ and $* P<0.05$ indicate significant differences ( $t$-test) in total infection thread number compared to groups at the same d.p.i. and indicated by matching coloured dots. Bars show s.e.m. for the total number of infection threads. See Supplementary Table 2 for extended statistical analysis. $n$ values are shown above each column.

b, c, Representative images of long (b) and short (c) infection threads observed from a. Scale bars, $20 \mu \mathrm{m}$.
Unlike R7AexoU, R7AexoB forms infected nodules on Gifu, albeit after a delay ${ }^{24}$ (Extended Data Fig. 6a).

Infection-thread formation was scored on Gifu, epr3-10 and epr311 at 10 and 14 d.p.i. with R7AexoB or R7A. The total number of infection threads in Gifu plants inoculated with R7AexoB was reduced to about half at 10 and 14 d.p.i. compared to R7A, suggesting a positive function of wild-type EPS (Fig. 3a). In reciprocal experiments infection-thread formation in R7A-inoculated epr3-10 and epr3-11 was reduced to about half, suggesting that EPR3 promotes efficient infection-thread initiation (Fig. 3a). A reduction in infectionthread formation was also observed in R7AexoB compared to R7Ainoculated epr3-10 and epr3-11 plants, possibly reflecting a passive physicochemical role of EPS. For both Gifu and the epr3 mutants the number of infection threads reaching the cortical boundary was significantly reduced at 10 and 14 d.p.i. compared to R7A-inoculated plants.

These observations demonstrate that both wild-type EPS and a functional EPR3 receptor are required for sustained infection-thread initiation. To substantiate a functional relationship between EPS and EPR3 further, the effect of purified EPS $\left(100 \mu \mathrm{g} \mathrm{ml}^{-1}\right)$ was examined on R7AexoB-inoculated Gifu and epr3-11 plants. A significant increase in infections threads was observed with Gifu while no increase was detected in epr3-11 (Fig. 4a). This Epr3-dependent positive effect of EPS addition supports the notion of a ligand-receptor relationship.

\section{EPS and truncated EPS are perceived}

Based on the inference that truncated EPS causes impaired infection, we sought to define the timing of the host perception and negative reaction. We inoculated Gifu, epr3-10 and epr3-11 mutants with R7AexoU and then after $15 \mathrm{~min}, 1 \mathrm{~h}, 24 \mathrm{~h}$ or $96 \mathrm{~h}$, inoculated these plants with either R7A or R7AexoB. Formation of infected nodules was scored at 14-42 d.p.i. If the second inoculation occurred within 24 $\mathrm{h}$, the prior inoculation with R7AexoU had no effect. This implies that the negative host reaction to truncated EPS is not immediate. However, when the second inoculation was delayed until $96 \mathrm{~h}$ after R7AexoU inoculation, an Epr3-dependent reduction in nodule numbers was observed (Extended Data Fig. 6b). Significantly fewer nodules developed on Gifu with R7AexoB compared to R7A as second inoculum. In contrast, this difference in R7AexoU sensitivity between R7A and R7AexoB was absent in epr3-10 or epr3-11 mutants. We infer that EPR3 perceives both truncated EPS and wild-type EPS, and that wild-type EPS can out-compete truncated EPS. In support of this interpretation an Epr3-dependent increase in infection-thread formation was observed after co-inoculation of R7AexoU with the Nodfactor-deficient but wild-type-EPS-producing R7A $\Delta \operatorname{nodA}^{33}$ (Fig. 4b).
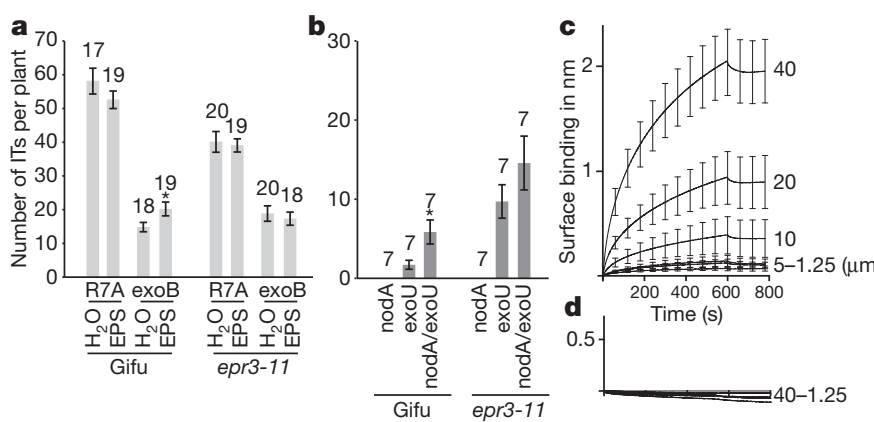

Figure $4 \mid$ EPS and truncated EPS are perceived by the EPR3 receptor. a, Frequency of infection threads (ITs) after addition of purified EPS to R7A or R7AexoB inoculated epr3-11 and Gifu. No effect of EPS addition was detectable on R7AexoU inoculated plants. b, R7A $\Delta$ nodA and R7AexoU co-inoculation of Gifu and epr3-11. ${ }^{*} P<0.05$ ( $t$-test). $n$ values are shown above each column. c, Sensorgrams show surface binding in $\mathrm{nm}$ as a result of binding of increasing concentrations of EPR 3 ectodomain to monomeric EPS. d, Corresponding sensorgrams for maltohexaose. Values from triplicate measurements; bars show s.e.m. 


\section{EPR3 perceives EPS directly}

The physical interaction between EPS and EPR3 was assessed in a binding assay using biolayer interferometry technology. EPR3 ectodomain protein was purified following baculovirus expression in insect cells (Extended Data Fig. 7) and octasaccharide EPS monomers were enriched from crude EPS (Extended Data Fig. 8a). EPS monomers were purified by size-exclusion chromatography, verified by mass spectrometry and chemoselectively labelled with biotin by aniline-catalysed oxime formation at the reducing end ${ }^{34}$ (Extended Data Fig. $8 \mathrm{~b}-\mathrm{e}$ ) to enable immobilization with streptavidin biosensors and affinity measurements. Biotin-functionalized maltohexaose was used as carbohydrate control. The sensorgrams obtained with EPS showed time- and EPR3-dependent association and dissociation while no detectable signal was obtained with the maltohexaose control (Fig. 4c, d). A $K_{\mathrm{d}}$ value of $2.7 \pm 0.2 \mu \mathrm{M}$ was determined for binding of monomeric EPS to the EPR3 ectodomain. This in vitro assay shows that EPR3 ectodomain can recognize monomeric EPS by direct binding and distinguish maltohexaose.

\section{Cellular localization of Epr3 expression}

Phenotypic characterization suggested EPR3 monitoring of EPS and control of bacterial passage through the root epidermis. Epr3 promoter activity was therefore investigated in transformed roots of Gifu using both an pEpr3::GUS reporter and an pEpr3::tYFP-NLS fusion localizing triple YFP protein in the nucleus. GUS activity was detected only in inoculated pEpr3::GUS transgenic roots at 3 d.p.i. (Fig. 5a, b). A more detailed study showed pEpr3::tYFP-NLS expression in epidermal cells in the susceptible root zone (Fig. $5 c-h$ ). A high level of YFP fluorescence was observed in root hairs with progressing infection threads (Fig. 5f-h), supporting a role for EPR3 in the control of epidermal infection.

\section{A two-step process controls infection}

In L. japonicus the primary signal transduction events activating infection and nodule organogenesis are triggered within minutes following the perception of Nod factors by the NFR1 and NFR5 receptors $^{31,35}$. To investigate whether EPR3 could substitute the function of NFR1 and/or NFR5 in Nod-factor perception, Epr3 was expressed in $n f r 1-1$ and $n f r 5-2$ mutants. In contrast to $N f r 1$ and $N f r 5$ expressed from cognate or 35 S promoters, full-length Epr3 (pEpr3::Epr3) and p35S::Epr3 did not restore nodulation (Extended Data Table 2b). To assess if the initial Nod-factor-mediated signalling was perturbed in epr3 mutants, the expression of two Nod-factorinduced genes, Nin and NfyAl, was measured following application of $10^{-8} \mathrm{M}$ purified Nod factors (Extended Data Fig. 3c, d). Although Nin expression differed between the epr3-10 mutant that possibly maintains residual kinase activity and the epr3-11 insertion mutant, expression of both genes was induced in Gifu, epr3-10 and epr3-11, indicating that EPR3 is not essential for Nod-factor perception. Under
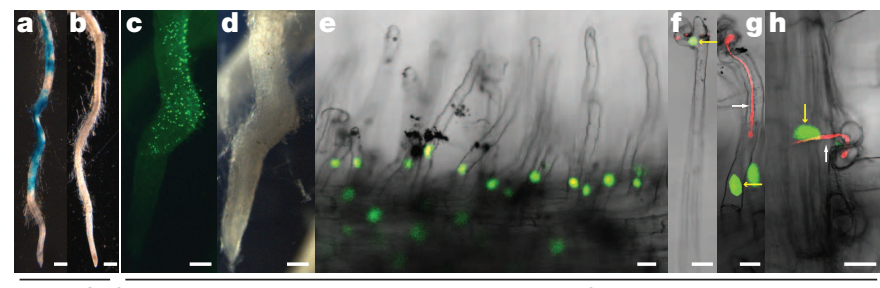

$\overline{p E p r 3:: G U S}$

pEpr3::tYFP-NLS

Figure $5 \mid$ EPR3 is Nod-factor-induced and expressed in epidermal cells. a, Expression of $p$ Epr3::GUS in R7A-inoculated root $(n=25)$. b, Noninoculated control $(n=15)$. c, d, $p E$ E 3 3: $:$ YFP-NLS expression in epidermal cells of the susceptible zone visualized as green fluorescent nuclei, yellow arrows $(n=20)$. e-h, $p$ Epr $3::$ YFF-NLS expression in root hairs $(n=20)$. Rhizobia were labelled with DsRed to show infection threads, white arrows. Scale bars: a-d, $500 \mu \mathrm{m}$; e-h, $20 \mu \mathrm{m}$. the same conditions, Epr3 expression was Nod-factor-induced in Gifu (Extended Data Fig. 3e). Supporting Nod-factor induction of Epr3, no pEpr3::GUS activity was detected in roots inoculated with an R7AnodC mutant unable to synthesize Nod factors ${ }^{33}$. In contrast, Epr3 and Nin expression was observed after inoculation with R7AexoU or R7AexoB (Extended Data Figs 3a, b and 4d, e).

\section{Discussion}

Here we describe a transmembrane receptor kinase, EPR3, and show that rhizobial access to legume roots is controlled by a two-stage mechanism. In L. japonicus two LysM receptors, NFR1 and NFR5, with high affinity for Nod factors trigger symbiotic signal transduction ${ }^{35,36}$. One consequence of this first recognition is Epr3 expression in root hairs and epidermal cells of the susceptible zone, and we propose that the EPR3 LysM receptor kinase then monitors the EPS status of bacteria during rhizobial infection (Fig. 6). Several lines of evidence support such a role for EPR3: (i) mutation of Epr3 suppresses the negative effect of truncated EPS; (ii) suppression of truncated EPS effects by normal EPS from R7A $\Delta$ nodA is Epr3-dependent; (iii) mutation of Epr3 and absence of EPS ligand in R7AexoB have comparable effects on infection; (iv) inhibition of EPS-deficient R7AexoB by truncated EPS from R7AexoU pre-inoculation is Epr3-dependent; (v) epr3 mutants display defective perception of purified EPS; and (vi) EPR3 ectodomain binds purified monomeric EPS directly. Taken together, our data also suggest that EPR3 distinguishes between EPS variants and acts positively in response to compatible EPS and negatively in response to incompatible EPS (Fig. 6). This explains the reduced infection rate of R7AexoB resulting from absence of a positive response, the positive response to EPS addition, and the abrogated infection of R7AexoU induced by a negative response.

Phenotypic characterization of epr3 mutants and EPS-addition experiments suggest that plant surveillance of bacterial EPS is exerted at the stage of colonization and infection of epidermal cells, irrespective of whether infection is intracellular through infection threads or intercellular by crack entry. We hypothesize that this recognition


Figure 6 Model for two-step receptor-mediated recognition of compatible rhizobia. a, Step 1: Colonization and host-specific initiation of infection triggered by Nod factor binding by NFR1 and NFR5 receptors leads to Epr3 expression in epidermal cells and root hair curling enclosing rhizobia. Step 2: NFR1 and NFR5 signalling continues and EPR3 perceives EPS. b-e, Tentative outcomes from EPR3 perception of compatible EPS and truncated EPS. $\mathbf{b}, \mathrm{A}$ basic level of EPR3 signalling promotes infection. c, Perception of compatible EPS increases signalling and promotes persistent infection. d, Truncated EPS activates a pathway blocking infection. e, Alternatively a co-receptor mechanism inhibits infection. 
increases basic signalling to a level required for sustained infection, most likely by amplifying ongoing Nod-factor-mediated signalling and/or suppressing plant defence responses (Fig. 6c and Extended Data Fig. 3b, c). In contrast, perception of incompatible EPS could possibly redirect signalling through a complex with a co-receptor, such as another LysM receptor or a lectin receptor (Fig. 6d, e). In all cases, perception of incompatible EPS may lead to mis-regulated gene activation or activation of a new set of downstream targets ${ }^{37,38}$. Inactivation of EPR3 in mutants diminishes this change in downstream signalling. As a result, EPR3 surveillance of EPS at the initiation of infection is lifted and infection threads or crack entry are initiated. Wild-type levels of infection are not obtained as epr3 mutations also eliminate the positive signalling required for sustained infection (Fig. 6c).

Taken together, our data show that EPS serves as a signal perceived by the EPR3 receptor. The ligand specificity, biochemical mechanisms and downstream consequences are a challenge for the future that may add new perspectives on carbohydrate signalling by LysM proteins that are represented across many forms of life, from bacteria to humans ${ }^{39,40}$.

Online Content Methods, along with any additional Extended Data display items and Source Data, are available in the online version of the paper; references unique to these sections appear only in the online paper.

\section{Received 8 February 2014; accepted 3 June 2015.} Published online 8 July 2015.

1. Chu, H. \& Mazmanian, S. K. Innate immune recognition of the microbiota promotes host-microbial symbiosis. Nature Immunol. 14, 668-675 (2013).

2. Flemming, H. C. \& Wingender, J. The biofilm matrix. Nature Rev. Microbiol. 8, 623-633 (2010).

3. Silipo, A. et al. Glyco-conjugates as elicitors or suppressors of plant innate immunity. Glycobiology 20, 406-419 (2010).

4. Becker, A., Fraysse, N. \& Sharypova, L. Recent advances in studies on structure and symbiosis-related function of rhizobial K-antigens and lipopolysaccharides. Mol. Plant Microbe Interact. 18, 899-905 (2005).

5. Fraysse, N., Couderc, F. \& Poinsot, V. Surface polysaccharide involvement in establishing the rhizobium-legume symbiosis. Eur. J. Biochem. 270, 1365-1380 (2003).

6. Jones, K. M., Kobayashi, H., Davies, B. W., Taga, M. E. \& Walker, G. C. How rhizobial symbionts invade plants: the Sinorhizobium-Medicago model. Nature Rev. Microbiol. 5, 619-633 (2007).

7. Desbrosses, G. J. \& Stougaard, J. Root nodulation: a paradigm for how plantmicrobe symbiosis influences host developmental pathways. Cell Host Microbe 10, 348-358 (2011).

8. Oldroyd, G. E. D., Murray, J. D., Poole, P. S. \& Downie, J. A. The rules of engagement in the legume-rhizobial symbiosis. Annu. Rev. Genet. 45, 119-144 (2011).

9. Fournier, J. et al. Mechanism of IT elongation in root hairs of Medicago truncatula and dynamic interplay with associated rhizobial colonization. Plant Physiol. 148, 1985-1995 (2008)

10. Xie, F. et al. Legume pectate lyase required for root infection by rhizobia. Proc. Nat Acad. Sci. USA 109, 633-638 (2012).

11. Breedveld, M. W. et al. Polysaccharide synthesis in relation to nodulation behavior of Rhizobium leguminosarum. J. Bacteriol. 175, 750-757 (1993).

12. Cheng, H. P. \& Walker, G. C. Succinoglycan is required for initiation and elongation of ITs during nodulation of alfalfa by Rhizobium meliloti. J. Bacteriol. $\mathbf{1 8 0}$ 5183-5191 (1998)

13. Wang, L. X., Wang, Y., Pellock, B. \& Walker, G. C. Structural characterization of the symbiotically important low-molecular-weight succinoglycan of Sinorhizobium meliloti. J. Bacteriol. 181, 6788-6796 (1999).

14. Skorupska, A., Janczarek, M., Marczak, M., Mazur, A. \& Krol, J. Rhizobial exopolysaccharides: genetic control and symbiotic functions. Microb. Cell Fact. $\mathbf{5}$ 7 (2006).

15. Aman, P., Franzen, L. E., Darvill, J. E. \& Albersheim, P. Structural eludication, using HPLC-MS and GLC-MS of the acidic polysaccharide secreted by Rhizobium meliloti strain 1021. Carbohydr. Res. 95, 263-282 (1981).

16. Reinhold, B. B. et al. Detailed structural characterization of succinoglycan, the major exopolysaccharide of Rhizobium meliloti Rm1021. J. Bacteriol. 176, 1997-2002 (1994)

17. Her, G. R., Glazebrook, J., Walker, G. C. \& Reinhold, V. N. Structural studies of a novel exopolysaccharide produced by a mutant of Rhizobium meliloti strain Rm1021. Carbohydr. Res. 198, 305-312 (1990).

18. Robertsen, B. K., Aman, P., Darvill, A. G., McNeil, M. \& Albersheim, P. Host-Symbiont Interactions. The structure of acidic extracellular polysaccharides secreted by Rhizobium leguminosarum and Rhizobium trifolii. Plant Physiol. 67, 389-400 (1981).
19. Battisti, L., Lara, J. C. \& Leigh, J. A. Specific oligosaccharide form of the Rhizobium meliloti exopolysaccharide promotes nodule invasion in alfalfa. Proc. Natl Acad. Sci. USA 89, 5625-5629 (1992).

20. Urzainqui, A. \& Walker, G. C. Exogenous suppression of the symbiotic deficiencies of Rhizobium meliloti exo mutants. J. Bacteriol. 174, 3403-3406 (1992).

21. Laus, M. C. van Brussel, A. A. \& Kijne, J. W. Role of cellulose fibrils and exopolysaccharides of Rhizobium leguminosarum in attachment to and infection of Vicia sativa root hairs. Mol. Plant Microbe Interact. 18, 533-538 (2005).

22. Aslam, S. N. et al. Bacterial polysaccharides suppress induced innate immunity by calcium chelation. Curr. Biol. 18, 1078-1083 (2008).

23. Lehman, A. P. \& Long, S. R. Exopolysaccharides from Sinorhizobium meliloti can protect against $\mathrm{H}_{2} \mathrm{O}_{2}$-dependent damage. J. Bacteriol. 195, 5362-5369 (2013).

24. Kelly, S. J. et al. Conditional requirement for exopolysaccharide in the Mesorhizobium-Lotus symbiosis. Mol. Plant Microbe Interact. 26, 319-329 (2013).

25. Lohmann, G. V. et al. Evolution and regulation of the Lotus japonicus LysM receptor gene family. Mol. Plant Microbe Interact. 23, 510-521 (2010).

26. Perry, J. A. et al. A TILLING reverse genetics tool and a web-accessible collection of mutants of the legume Lotus japonicus. Plant Physiol. 131, 866-871 (2003).

27. Fukai, E. etal. Establishment of a Lotus japonicus gene tagging population using the exon-targeting endogenous retrotransposon LORE1. Plant J. 69, 720-730 (2012).

28. Urbański, D. F., Malolepszy, A., Stougaard, J. \& Andersen, S. U. Genome-wide LORE1 retrotransposon mutagenesis and high-throughput insertion detection in Lotus japonicus. Plant J. 69, 731-741 (2012).

29. Tanaka, K. et al. Role of LysM receptors in chitin-triggered plant innate immunity. Plant Signal. Behav. 8, e22598 (2013).

30. Liu, T. et al. Chitin-induced dimerization activates a plant immune receptor. Science 336, 1160-1164 (2012).

31. Madsen, L. H. et al. The molecular network governing nodule organogenesis and infection in the model legume Lotus japonicus. Naure Commun. 1, 10 (2010).

32. Tirichine, L. et al. spontaneous root-nodule formation in the model legume Lotus japonicus: a novel class of mutants nodulates in the absence of rhizobia. Mol. Plant Microbe Interact. 19, 373-382 (2006).

33. Rodpothong, P. et al. Nodulation gene mutants of Mesorhizobium loti R7A-nodZ and nol $\mathrm{L}$ mutants have host-specific phenotypes on Lotus spp. Mol. Plant Microbe Interact. 22, 1546-1554 (2009).

34. Thygesen, M. B. et al. Nucleophilic catalysis of carbohydrate oxime formation by anilines. J. Org. Chem. 75, 1752-1755 (2010).

35. Radutoiu, S. et al. Plant recognition of symbiotic bacteria requires two LysM receptor-like kinases. Nature 425, 585-592 (2003).

36. Broghammer, A. et al. Legume receptors perceive the rhizobial lipochitin oligosaccharide signal molecules by direct binding. Proc. Natl Acad. Sci. USA 109, 13859-13864 (2012)

37. Høgslund, N. et al. Dissection of symbiosis and organ development by integrated transcriptome analysis of Lotus japonicus mutant and wild-type plants. PLOS ONE 4, e6556 (2009).

38. Jones, K. M. et al. Differential response of the plant Medicago truncatula to its symbiont Sinorhizobium meliloti or an exopolysaccharide-deficient mutant. Proc. Natl Acad. Sci. USA 105, 704-709 (2008).

39. Laroche, F. J. etal. The embryonic expression patterns of zebrafish genes encoding LysM-domains. Gene Expr. Patterns 13, 212-224 (2013).

40. Wong, J. E. M. M. et al. An intermolecular binding mechanism involving multiple LysM domains mediates carbohydrate recognition by an endopeptidase. Acta Crystallogr. D 71, 592-605 (2015).

Supplementary Information is available in the online version of the paper.

Acknowledgements This work was supported by the Danish National Research Foundation grant no. DNRF79 and the ERC Advanced Grant 268523. We thank S. Bucholdt for technical help with Epr3 promoter-GUS fusions, T. Brock-Nannestad for technical assistance with FT-ICR mass spectrometry and J. Sullivan for comments on the manuscript. A.M. and R.W.C. were supported by the Chemical Sciences, Geosciences and Biosciences Division, Office of Basic Energy Sciences, US Department of Energy grant (DE-FG02-93ER20097) to the DOE Center for Plant and Microbial Complex Carbohydrates at the Complex Carbohydrate Research Center.

Author Contributions Y.K., identification of EMS and LORE1 epr3 mutations, characterization of the Epr3 gene, and phenotypic characterization; S.K., phenotypic characterization; M.W.N., identification of TILLING epr3 mutations, characterization of the Epr3 gene, complementation experiments; C.T.H. and M.B.T., biotin tagging of EPS and maltohexaose and affinity studies; K.G. and M.V., purification of EPR3 ectodomain and affinity studies; A.M., R.W.C. and C.T.H., purification and characterisation of monomeric EPS; N.S. screening for suppressor mutants and isolation of the epr3-10 allele; M.H.A., technical assistance; S.U.A., analysis of next-generation sequencing data; L.K., localization in N. benthamiana; K.J.J., S.T. and C.W.R. conceived experiments; M.B. and S.R. conceived and coordinated experiments; J.S. conceived experiments and coordinated. JS wrote the manuscript with input from Y.K., S.K., M.W.N., M.B., C.T.H., M.B.T., A.M., C.W.R. and S.R

Author Information The Epr3 gene sequence has been deposited in GenBank under accession number AB506700.1. Reprints and permissions information is available at www.nature.com/reprints. The authors declare no competing financial interests. Readers are welcome to comment on the online version of the paper. Correspondence and requests for materials should be addressed to J.S. (stougaard@mbg.au.dk). 


\section{METHODS}

Plant material and growth conditions. Seeds were treated with concentrated sulfuric acid, surface sterilized in $0.5 \%$ bleach and germinated on wet filter paper for 3 days as previously described ${ }^{41}$. Seeds with emerging radicles were transferred to square Petri dishes with agar slopes (plates) or magenta boxes (Sigma-Aldrich) containing $0.25 \times \mathrm{B} \& \mathrm{D}$ medium $^{42}$. The plate medium was solidified with $1.4 \%$ Agar Noble (Difco) and the surface of the slope was covered with filter paper (AGF 651, Frisenette ApS). A metal bar with 3-mm holes for roots was inserted at the top of the agar slope. Plates were incubated in an upright position in specially fabricated boxes, excluding light from the roots below the metal bar. Magenta boxes containing lightweight expanded clay aggregate (LECA, Saint-Gobain Weber A/S, http://www.weber.dk, 2-4 mm diameter) and vermiculite size $\mathrm{M}$ (Damolin A/S, http://www.damolin.dk) in a 4:1 mixture were supplemented with $60 \mathrm{ml} 0.25 \times \mathrm{B} \& \mathrm{D}$. Plants were incubated at $21{ }^{\circ} \mathrm{C}$ under a $16 \mathrm{~h}$ light $/ 8 \mathrm{~h}$ dark cycle. For nodulation studies plates containing ten plants each were inoculated with 500-1,000 $\mu \mathrm{l}$ of $M$. lot $i$ at an optical density of $\mathrm{OD}_{600}=0.02-0.05$.

Bacterial strains and growth conditions. Wild-type $M$. loti strain $\mathrm{R}^{4} \mathrm{~A}^{43,44}$ and strains R7AexoU, R7AexoB, R7A $\Delta$ nodA and R7AnodC derived from R7A were grown in TY/YMB medium at $28{ }^{\circ} \mathrm{C}$. The corresponding stains constitutively expressing DsRed or lac $Z$ were obtained through the introduction of plasmids pSKDSRED $^{24}$ or pXLGD4 ${ }^{45}$, respectively, and were used for the visualization of infection threads. Roots used for counting infection threads were inspected using a Zeiss Axioplan 2 image fluorescence microscope. Bacteria expressing lacZ within infection threads were visualized as previously described ${ }^{46}$. Infection threads were also visualized following staining of roots in $0.01 \%$ toluidine blue for $1 \mathrm{~min}$ and rinsing in several changes of $\mathrm{H}_{2} \mathrm{O}$. Agrobacterium rhizogenes strains AR12 or AR1193 ${ }^{47,48}$ were used for all hairy root transformation experiments according to previously described methods ${ }^{49}$. The following concentrations of antibiotics were used for $M$. loti and A. rhizogenes strains: ampicillin, $100 \mu \mathrm{g} \mathrm{ml}^{-1}$; tetracycline, $2-10 \mu \mathrm{g} \mathrm{ml}^{-1}$; gentamicin, $50 \mu \mathrm{g} \mathrm{ml}^{-1}$; rifampicin, $100 \mu \mathrm{g} \mathrm{ml}^{-1}$; spectinomycin, $100 \mu \mathrm{g} \mathrm{ml}^{-1}$; neomycin, $100 \mu \mathrm{g} \mathrm{ml}^{-1}$.

Suppressor screen. Seeds from L. japonicus ecotype $\mathrm{Gifu}^{41}$ were treated with ethyl methanesulfonate (EMS) and $N$-ethyl- $N$-nitrosourea (ENU) and M2 plants of self-fertilized M1 plants were inoculated with the R7AexoU strain. In the primary screen, 500 to 1,000 plants originating from ten M1 seeds pools were grown in autoclaved trays $(35 \times 55 \times 25 \mathrm{~cm})$ containing LECA and vermiculite in a 3:1 mix and $510.25 \times \mathrm{B} \& \mathrm{D}$ for 6 to 8 weeks in greenhouse conditions. To avoid flooding the plant roots a metal plate covered with cloth was placed in the bottom of the trays. Based on nodulation and growth phenotypes approximately $500 \mathrm{M} 2$ plants from 1,246 M1 pools were identified as putative suppressor mutants and transferred to soil for seed production. Subsequently, progeny from these putative suppressor mutants were tested for inheritance of the observed phenotype using the square plate setup described above at $21^{\circ} \mathrm{C}$ in growth cabinets. This procedure identified the exo277 (epr3-10) suppressor mutant line. Finally an epr3 allelic mutant series was established from lines obtained from the Lotus TILLING facility (RevGenUK, http://revgenuk.jic.ac.uk/) and from the LORE1 insertional mutagenesis project (http://users-mb.au.dk/pmgrp/index.html). All mutants were genotyped using the primers listed in Supplementary Table 1.

Genetic analysis. The mutation carried by the exo277 (epr3-10) suppressor line was mapped using a F2 population established from a cross to L. japonicus ecotype MG113 obtained from Legume Base (http://www.legumebase.brc.miy azaki-u.ac.jp/). Marker information was obtained from deep sequencing of the MG113 genome and comparison towards the Gifu genome sequence. A list of SSR, indel and SNP markers is shown in Supplementary Table 3.

Protein analysis. BlastP (http://blast.ncbi.nlm.nih.gov/Blast.cgi) was used to find EPR3 homologues from other plants. Clustal Omega (http://www.ebi.ac.uk/ Tools/msa/clustalo/) was used for multiple sequence alignment. The phylogenetic analysis was performed using the CLC Main Workbench v6.5. SignalP 4.1 Server (http://www.cbs.dtu.dk/services/SignalP/) and TMHMM Server v2.0 (http://www.cbs.dtu.dk/services/TMHMM-2.0/) predicted signal peptides and transmembrane domains. PSIPRED (http://bioinf.cs.ucl.ac.uk/psipred/) was used for secondary structure prediction.

Expression and purification of the EPR3 ectodomain. The Epr3 ectodomain nucleotide sequence was codon-optimized for insect cell expression (GeneScript Piscataway) and engineered with an N-terminal gp67 signal peptide and a C-terminal hexahistidine tag. The insert was cloned into the transfer vector pOET2 (Oxford Expression Technologies) and recombinant baculoviruses were obtained with the flashBAC GOLD system (OET) according to the manufacturer's instructions. Sf9 cells $\left(1.5 \times 10^{6}\right.$ cells per ml $)$ cultured at $26^{\circ} \mathrm{C}$ in suspension in serum-free HyClone SFX-Insect medium (FisherScientific) supplemented with $100 \mathrm{U}^{-1}$ penicillin/streptomycin (Life technologies) and $1 \%(\mathrm{v} / \mathrm{v}) \mathrm{chem}$ ically defined lipid concentrate (Gibco) were infected with recombinant passage 3 virus particles $(20 \mathrm{ml}$ per 1 of culture). After expression for 5 days, medium supernatant was harvested by centrifugation and was subjected to an overnight dialysis step against $50 \mathrm{mM}$ Tris- $\mathrm{HCl} \mathrm{pH} 8.0,200 \mathrm{mM} \mathrm{NaCl}$ at room temperature.

EPR3 ectodomain was purified from the medium by Ni-IMAC using a HisTrap excel affinity column (GE Healthcare). The protein was eluted with $50 \mathrm{mM}$ Tris$\mathrm{HCl}, 200 \mathrm{mM} \mathrm{NaCl}$ and $500 \mathrm{mM}$ imidazole. After dialysis against $50 \mathrm{mM}$ Tris$\mathrm{HCl} \mathrm{pH}$ 8.0, $200 \mathrm{mM} \mathrm{NaCl}$, EPR3 ectodomain was further purified by another step of Ni-IMAC using a HisTrap HP affinity column (GE Healthcare). After elution and subsequent concentration, the purification was finalized by a SEC step on a Superdex 75 10/300 GL column connected to an ÄKTA Purifier system (GE Healthcare) in a buffer containing PBS, pH 7.2. The protein is expressed in different glycosylation states, visible as distinct bands on an SDS-PAGE gel.

Purification of monomeric exopolysaccharide. A monomeric EPS was recovered from minimal G/RDM culture media by sequential precipitation with absolute $\mathrm{EtOH}$. Initially high molecular weight polysaccharides were precipitated with three volumes of EtOH (v/v) as previously described ${ }^{24}$. The remaining supernatant was concentrated down by rotary evaporation and the low-molecular-weight oligosaccharides were recovered from the solution by additional precipitation with nine volumes of $\mathrm{EtOH}(\mathrm{v} / \mathrm{v})$.

Crude nine-volume EtOH precipitate was dialysed against deionized $\mathrm{H}_{2} \mathrm{O}$ using SpectraPor $1000 \mathrm{MWCO}$ tubing, at $4{ }^{\circ} \mathrm{C}$. Concentrated dialysate was filtered through nylon centrifuge filter $(0.22 \mu \mathrm{m}$ pore size) and fractionated on Superdex Peptide 10/300 GL column (GE Healthcare Life Sciences), assembled with Agilent Technologies 1200 Series system, with $50 \mathrm{mM}$ ammonium acetate buffer pH 6.7 (BioXtra, $\geq 98 \%$, Sigma Aldrich) used as the eluent. The $48 \mathrm{~min}$ separation was carried out in isocratic condition, and with $0.5 \mathrm{ml} \mathrm{min}{ }^{-1}$ column flow, at room temperature. Eluting fractions were simultaneously evaluated with a refractive index detector (RID-10A, Shimadzu) and multiple wavelength detector (Agilent Technologies 1200 Series) at $\lambda=210,230$ and $280 \mathrm{~nm}$, respectively. The fractions giving positive response in RID were pooled, frozen and ammonium acetate buffer was evacuated by multiple freeze-drying cycles. The quality of monomeric EPS was evaluated by MALDI mass spectrometry and by NMR analysis (A. Muszyński, personal communication, 2015).

MALDI-TOF mass spectrometry analysis of monomeric polysaccharide. Monomeric EPS fraction was dissolved in water and mixed 1:1 (v/v) with either 0.5 M Super-DHB (9:1 mixture of DHB and 2-hydroxy-5-methoxybenzoic acid) or 0.5 M THAP (2,4,6-trihydroxyacetophenone monohydrate) matrix in meth anol and spotted onto a stainless steel target plate. MALDI spectra were recorded in the negative reflector ionization mode using Applied Biosystem's AB SCIEX TOF/TOF 5800 system.

Synthesis of EPS octaose-biotin and maltohexaose-biotin conjugates. Carbohydrates were conjugated to biotin following an approach analogous to the one described by Broghammer et al. ${ }^{36}$. Heterobifunctional aminooxy-thiol OEG linker, O-(2-(2-(2-(2-tritylsulfanylethoxy)ethoxy)ethoxy)ethyl)hydroxylamine, was prepared as described previously ${ }^{50}$. All other chemicals were purchased from Sigma-Aldrich, and used without further purification. Liquid chromatography-mass spectrometry (LCMS) was performed on a UltiMate 3000 UHPLC $^{+}$ focused system, fitted with a Thermo Fisher MSQ Plus ESI MS, using a Phenomenex Gemini $5 \mu \mathrm{m}, \mathrm{C} 18,110 \AA$ А, $50 \times 4.6 \mathrm{~mm}$ analytical column, and using a gradient of $5-100 \%$ acetonitrile in water containing $0.1 \%$ formic acid Preparative high-performance liquid chromatography (HPLC) was performed on a UltiMate 3000 instrument fitted with a Waters 996 photodiode detector, using a Phenomenex Luna $5 \mu \mathrm{m}, \mathrm{C} 18(2), 100 \AA$, $250 \times 100 \mathrm{~mm}$ semi-preparative column. Both conjugates were purified using a gradient of $5-60 \%$ acetonitrile in water containing $0.1 \%$ formic acid, and with a flow rate of $5 \mathrm{ml} \mathrm{min}{ }^{-1}$. Highresolution mass spectrometry (HRMS) was performed on a Bruker Solarix

XR ESI/MALDI-FT-ICR-MS instrument equipped with a $7 \mathrm{~T}$ magnet. The instrument was run in ESI-mode and externally calibrated with NaOTFA cluster ions. Data was processed using Bruker Data Analysis 4.1. Purified EPS octaose ( $1.7 \mathrm{mg}, 1.18 \mu \mathrm{mol}, 5 \mathrm{mM}$ ) was dissolved in $50 \mathrm{mM} \mathrm{NaOAc}$ buffer containing $50 \mathrm{mM}$ aniline in $\mathrm{MeCN}-\mathrm{H}_{2} \mathrm{O}$ (1:1), $\mathrm{pH} 4.5$, and aminooxy-thiol OEG linker $(10 \mathrm{mM})$ was added ${ }^{34}$. The resulting mixture was allowed to react at $40{ }^{\circ} \mathrm{C}$ for $16 \mathrm{~h}$. Conjugate oxime formation was confirmed by LCMS. MS (ESI) calculated for $[\mathrm{M}+\mathrm{H}, 3 \mathrm{Ac}]^{+}=1,888.6$, found $1,889.0$, and calculated for $[\mathrm{M}+\mathrm{H}, 2 \mathrm{Ac}]^{+}=$ 1,846.6, found 1,846.9. The mixture was concentrated under a $\mathrm{N}_{2}$ flow, and triturated three times with $n$-heptane to remove excess linker. To the residue was added a $5 \%$ solution of triethylsilane in trifluoroacetic acid (5 ml). After $15 \mathrm{~min}$ at room temperature the mixture was concentrated under a $\mathrm{N}_{2}$ flow and triturated three times with $n$-heptane. The residue was dissolved in $50 \mathrm{mM}$ $\mathrm{Na}_{2} \mathrm{~B}_{4} \mathrm{O}_{7}$ buffer, $\mathrm{pH} 8.3$, to a concentration of EPS of $2.5 \mathrm{mM}$, upon which $\mathrm{N}$-(2-(2-(2-(biotinylamido)ethoxy)ethoxy)ethyl)-2-iodoacetamide $(5 \mathrm{mM})$ was added $^{50}$. The reaction was conducted at room temperature for $15 \mathrm{~min}$, after which the product was purified by preparative HPLC. The chromatogram displayed several overlapping peaks, owing to microheterogenity in the distribution of 
OAc groups, ranging from one to three OAc groups. The EPS octamer-biotin conjugate (27\% yield) was quantified using the $\mathrm{HABA}$-avidin biotin-quantification kit from Pierce. HRMS (FT-ICR) calculated for: $[\mathrm{M}+\mathrm{H}, 3 \mathrm{Ac}]^{+}=2,060.7067$, found 2,060.7066, and calculated for $[\mathrm{M}+\mathrm{H}, 2 \mathrm{Ac}]^{+}=2,018.6961$, found $2,018.7004$, and calculated for $[\mathrm{M}+\mathrm{H}, 1 \mathrm{Ac}]^{+}=1,976.6856$, found $1,976.6888$, and calculated for $[\mathrm{M}+2 \mathrm{H}, 3 \mathrm{Ac}]^{2+}=1,030.8574$, found $1,030.8559$, and calculated for $[\mathrm{M}+2 \mathrm{H}, 2 \mathrm{Ac}]^{2+}=1,009.8521$, found $1,009.8514$, and calculated for $[\mathrm{M}+2 \mathrm{H}, 1 \mathrm{Ac}]^{2+}=988.8468$, found 988.8463 .

The synthesis of a maltohexose-biotin conjugate was performed essentially as for the EPS-biotin conjugate. HRMS (FT-ICR) calculated for $[\mathrm{M}+\mathrm{H}]^{+}=1,612.6252$, found $1,612.6214$.

Biolayer interferometry binding studies. EPR3 ectodomain interaction with EPS octamer was measured on an Octet RED biolayer interferometer (Pall ForteBio) that measures wavelength shift $(\Delta \lambda)$ of reflected white light in real time. Binding of a protein to immobilized ligand ${ }^{51}$ will change the optical thickness of a biosensor resulting in a quantifiable wavelength shift (see http://www.fortebio. com/bli-technology.html). Biotinylated EPS octaose, and maltohexaose as control, were immobilized on streptavidin biosensors (Pall ForteBio) at a concentration of $250 \mathrm{nM}$ for $5 \mathrm{~min}$. Immobilization levels were identical for the EPS and maltohexaose conjugates, amounting to approximately $0.6 \mathrm{~nm}$ and $0.5 \mathrm{~nm}$, respectively. Interaction with EPR3 ectodomain was measured in dilution series at protein concentrations ranging from $1.25-40 \mu \mathrm{M}$ in phosphate buffered saline, $\mathrm{pH} 7.0$, with $0.01 \%$ Tween 20 , at $30{ }^{\circ} \mathrm{C}$ for $10 \mathrm{~min}$. Subsequently, dissociation was conducted in protein-free phosphate buffered saline, $\mathrm{pH} 7.0$, with $0.01 \%$ Tween 20 , at $30{ }^{\circ} \mathrm{C}$ for $3 \mathrm{~min}$. Background measurements using biosensors immobilized with free biotin were subtracted from EPS and maltohexaose data in order to account for unspecific binding. Sensorgrams were aligned to the baseline using ForteBio Data Analysis 7.0 (Pall ForteBio), and data processing with GraphPad PRISM 6.05 software yielded a $K_{\mathrm{d}}=2.7 \pm 0.2 \mu \mathrm{M}$ from triplicate measurements with EPR3 ectodomain.

Expression analysis. For expression analysis in roots, plants were grown and Nod factors applied modifying a method previously described ${ }^{52}$. mRNA was isolated from Nod-factor-treated $\left(10^{-8} \mathrm{M}\right)$ roots using Dynabeads mRNA DIRECT kit (Invitrogen). RevertAid M-MuLV Reverse Transcriptase (Fermentas) was used for cDNA synthesis. All cDNA samples were tested for genomic DNA contamination using primers specific for the Nin gene $\operatorname{promoter}^{25}$. A Lightcycler480 instrument and Lightcycler480 SYBR Green I master (Roche Diagnostics $\mathrm{GmbH}$ ) was used for the real time quantitative PCR. ATP-synthase (ATP), ubiquitin-conjugating enzyme $(U B C)$ and protein phosphatase $2 \mathrm{~A}(P P 2 A)$ were used as reference genes ${ }^{53}$. Melting curve analyses and sequencing of all the amplified products were performed to verify the specificity of the primers. The relative quantification software (Roche) was used to calculate the normalized efficiency-corrected relative transcript levels. The geometric mean of the relative transcript levels for the three biological (each consisting of ten plants) and three technical repetitions and the corresponding upper and lower $95 \%$ confidence were calculated ${ }^{54}$. Epr 3 , Nin, NfyA1 and reference genes primers are listed in Supplementary Table 4

Transformation of Nicotiana benthamiana leaves. The Epr3::YFP-HA construct was obtained by amplifying the Epr3 cDNA sequence (without the stop codon) with primers containing attB sites and a thrombin site following the attB2 site in the reverse primer. The amplified product was recombined into the pDONR207 vector (Invitrogen) in a Gateway BP reaction (Invitrogen), which further recombined with the vector $p$ Earleygate $101^{55}$ in the Gateway LR reaction (Invitrogen) to construct pEarleygate::p35S::Epr3::YFP-HA.

A. tumefaciens strain AGL1 transformed with the pEarleygate::p35S::Epr3:: YFP-HA expression clone was grown to high density in liquid culture, centrifuged at $1300 \mathrm{~g}$ and suspended in $10 \mathrm{mM}$ Mes-KOH, $10 \mathrm{mM} \mathrm{MgCl}_{2}$ and $0.15 \mathrm{mM}$ aceteosyringone. The culture was diluted to $\mathrm{OD}_{600}=0.2$ and mixed with a $1 / 10$ volume of an $A$. tumefaciens culture expressing the silencing suppressor $\mathrm{p} 19^{56}$. Leaves of 3-4-week-old $N$. benthamiana plants were infiltrated with the mix and analysed at 3 days post infiltration using a Zeiss LSM510 META confocal microscope. For co-localization of EPR3-eYFP with the plasma membrane the membrane dye FM 4-64 (Invitrogen) was used.

Promoter GUS and $\mathbf{T Y F P}-\mathbf{N L S}$ analysis. A putative Epr3 promoter region of 1,016 bp was amplified from $L$. japonicus Gifu genomic DNA by PCR using primers containing $a t t B$ sites and recombined into $p D O N R 207$ (Invitrogen) using the Gateway BP reaction (Invitrogen) to create the entry clone pDONR207:: pEpr3. The entry clone was recombined using Gateway LR reactions (Invitrogen) with destination vectors $p I V 10:: G W:: G U S$ and $p I V 10:: G W:: t Y F P$ NLS (D. Reid, personal communication, 2014) to create the pIV10::pEpr3::GUS and pIV10::pEpr3::tYFP-NLS constructs. The plasmids containing these promoter fusions were transformed into $A$. rhizogenes.
The pIV10::pEpr3::GUS and pIV10::pEpr3::tYFP-NLS constructs in A. rhizogenes were transformed into $L$. japonicus as previously described ${ }^{47}$. Transformed plants were transferred to Magenta boxes and grown for a week before inoculation with $1,000 \mu \mathrm{l}$ of a dilution $\left(\mathrm{OD}_{600}=0.01-0.02\right)$ of $M$. loti strain R7A DsRed or MAFF303099 DsRed per plant. For $p E p r 3:: t Y F P-N L S$ analysis, transgenic roots were observed for nuclear fluorescence using a Zeiss LSM510 META confocal microscope. For pEpr3::GUS and pNin::GUS analysis, roots were stained using GUS-staining buffer (0.05 M sodium phosphate buffer pH 7.0, $10 \mathrm{mM}$ EDTA, $20 \%$ methanol (v/v), $50 \mathrm{mg} \mathrm{ml}^{-1} \mathrm{X}$-gluc dissolved in DMSO) at $37^{\circ} \mathrm{C}$ overnight. Stained roots were washed with $70 \%(\mathrm{v} / \mathrm{v})$ ethanol and stored at $4{ }^{\circ} \mathrm{C}$. Root and nodule sections used for visualizing the spatial GUS activity were obtained using a Leica M165 FC stereomicroscope.

Nodule sectioning. Two- to six-week-old nodules induced by $M$. loti lac $Z$ were fixed with $1.25 \%$ glutaraldehyde in $0.1 \mathrm{M}$ phosphate buffer, and then stained in LacZ reaction buffer $\left(0.1 \mathrm{M}\right.$ sodium phosphate buffer $\mathrm{pH} 7.0,0.64 \mathrm{mg} \mathrm{ml}^{-1} \mathrm{X}$-gal dissolved in $\mathrm{N}$-methyl-2-pyrvalidone, $5 \mathrm{mM}$ potassium ferrocyanide, $5 \mathrm{mM}$ potassium ferricyanide, $0.1 \%(\mathrm{w} / \mathrm{v}))$ at room temp overnight. The nodule samples were embedded in 3\% agarose in water, sliced in thick layer sections (50 to $100 \mu \mathrm{m}$ ) using a Leica VT 1000S vibratome. For semi-thin layer sections, nodules were fixed in a mixture of $4 \%(\mathrm{w} / \mathrm{v})$ paraformaldehyde and $1 \%$ glutaraldehyde in $0.1 \mathrm{M}$ phosphate buffer $\mathrm{pH}$ 7.2. Samples were then embedded using a Technobit 7100 (Heraeus Kulzer), sliced in semi-thin layer sections $(7 \mu \mathrm{m})$ using a Leica RM2045 microtome, and then mounted onto microscope slides. Sections were stained with $0.1 \%$ toluidine blue in water and observed using a Zeiss Axioplan 2 image fluorescence microscope.

Competition analysis. L. japonicus Gifu seedlings, on square growth plates, were inoculated with $1 \mathrm{ml}$ of an $\mathrm{OD}_{600}=0.02 \mathrm{R} 7 \mathrm{AexoU}$ suspension per plate and grown at $21^{\circ} \mathrm{C}$ for $15 \mathrm{~min}, 1 \mathrm{~h}, 24 \mathrm{~h}$ and $96 \mathrm{~h}$ before subsequent inoculation with $1 \mathrm{ml}$ of an $\mathrm{OD}_{600}=0.02 \mathrm{R} 7 \mathrm{~A}$ or R7AexoB suspension. In control experiments the symbiotically impaired Nod factor mutant R7A $\Delta$ nodA was used as the initial inoculum. A 1:1 mixture of R7AexoU and R7A $\Delta$ nodA was used in the coinoculation study (Fig. 4b and Extended Data Fig. 6). For EPS treatment experiment, Gifu and epr3-11 seedlings were inoculated with $1 \mathrm{ml}$ R7AexoB DsRed $\left(\mathrm{OD}_{600}=0.02\right)$ per plate. After $72 \mathrm{~h}, 100 \mu \mathrm{g} \mathrm{ml}^{-1}$ of LMW EPS purified from R7A $\Delta \mathrm{ndvB}$ or sterile water was added. Plants were grown at $21^{\circ} \mathrm{C}$ for 7 days, and infection threads were counted.

Constructs for complementation of $\boldsymbol{n f r} \mathbf{1}$ and $\boldsymbol{n f r} 5$ mutants. A full-length genomic Epr 3 construct containing 1,016 bp upstream from the start codon and 2,014 bp downstream of the stop codon was amplified by PCR and cloned into $p E N T E R$ vector (Invitrogen), to construct the entry clone named pENTER::pEpr3::Epr3. The entry clone was recombined using Gateway LR reactions (Invitrogen) with destination vectors named $p I V 10:: G W$, to construct $p I V 10:: p E p r 3:: E p r 3$. The construct $p 35 S:: E p r 3:: t 35 S$ was obtained by amplifying the Epr3 cDNA sequence from start to stop codon with primers containing attB sites and recombining into the $p D O N R 207$ vector (Invitrogen) which was further recombined with the destination vector $p I V 10:: p 35 S:: G W:: t 35 S$ in a Gateway LR reaction (Invitrogen) creating the expression clone pIV10::p35S::Epr3::t35S.

Data reporting. No statistical methods were used to predetermine sample size. The experiments were not randomized. The investigators were not blinded to allocation during experiments and outcome assessment.

41. Handberg, K. \& Stougaard, J. Lotus japonicus, an autogamous, diploid legume species for classical and molecular genetics. Plant J. 2, 487-496 (1992).

42. Broughton, W. J. \& Dilworth, M. J. Control of leghaemoglobin synthesis in snake beans. Biochem. J. 125, 1075-1080 (1971).

43. Sullivan, J. T. et al. Comparative sequence analysis of the symbiosis island of Mesorhizobium loti strain R7A. J. Bacteriol. 184, 3086-3095 (2002).

44. Kelly, S. et al. Genome sequence of the Lotus spp. microsymbiont Mesorhizobium loti strain R7A. Stand. Genomic Sci. 9, 6 (2014).

45. Leong, S. A., Williams, P. H. \& Ditta, G. S. Analysis of the 5 ' regulatory region of the gene for delta-aminolevulinic acid synthetase of Rhizobium meliloti. Nucleic Acids Res. 13, 5965-5976 (1985)

46. Kawaharada, Y., Eda, S., Minamisawa, K. \& Mitsui, H. A Mesorhizobium loti mutant with reduced glucan content shows defective invasion of its host plant Lotus japonicus. Microbiology 153, 3983-3993 (2007).

47. Hansen, J., Jørgensen, J.-E., Stougaard, J. \& Marcker, K. Hairy roots - a short cut to transgenic root nodules. Plant Cell Rep. 8, 12-15 (1989).

48. Stougaard, J., Abildsten, D. \& Marcker, K. The Agrobacterium rhizogenes pRi TLDNA segment as a gene vector system for transformation of plants. Mol. Gen. Genet. 207, 251-255 (1987).

49. Petit, A. et al. Transformation and regeneration of the legume Lotus corniculatus: A system for molecular studies of symbiotic nitrogen fixation. Mol. Gen. Genet. 207, 245-250 (1987).

50. Thygesen, M. B., Sauer, J. \& Jensen, K. J. Chemoselective capture of glycans for analysis on gold nanoparticles: carbohydrate oxime tautomers provide functional recognition by proteins. Chemistry 15, 1649-1660 (2009). 


\section{RESEARCH ARTICLE}

51. Xiong, X. et al. Receptor binding by an H7N9 influenza virus from humans. Nature 499, 496-499 (2013).

52. Heckmann, A. B. et al. Cytokinin induction of root nodule primordia in Lotus japonicus is regulated by a mechanism operating in the root cortex. Mol. Plant Microbe Interact. 24, 1385-1395 (2011).

53. Czechowski, T., Stitt, M., Altmann, T.,Udvardi, M. K. \& Scheible, W. R. Genome-wide identification and testing of superior reference genes for transcript normalization in Arabidopsis. Plant Physiol. 139, 5-17 (2005)

54. Vandesompele, J. et al. Accurate normalization of real-time quantitative RT-PCR data by geometric averaging of multiple internal control genes. Genome Biol. 3, 7 (2002).

55. Earley, K. W. et al. Gateway-compatible vectors for plant functional genomics and proteomics. Plant J. 45, 616-629 (2006)

56. Voinnet, O., Rivas, S., Mestre, P.\& Baulcombe, D. An enhanced transient expression system in plants based on suppression of gene silencing by the 19 protein of tomato bushy stunt virus. Plant J. 33, 949-956 (2003).
57. Hayashi, M. et al. Construction of a genetic linkage map of the model legume Lotus japonicus using an intraspecific F2 population. DNA Res. 8, 301-310 (2001)

58. Sandal, N. et al. A genetic linkage map of the model legume Lotus japonicus and strategies for fast mapping of new loci. Genetics 161, 1673-1683 (2002).

59. Krusell, L. et al. Shoot control of root development and nodulation is mediated by a receptor-like kinase. Nature 420, 422-426 (2002).

60. Nishimura, R. et al. HAR1 mediates systemic regulation of symbiotic organ development. Nature 420, 426-429 (2002)

61. Tirichine, L. et al. Deregulation of a $\mathrm{Ca}^{2+}$ /calmodulin-dependent kinase leads to spontaneous nodule development. Nature 441, 1153-1156 (2006).

62. Tirichine, L. et al. A gain-of-function mutation in a cytokinin receptor triggers spontaneous root nodule organogenesis. Science 315, 104-107 (2007). 
a



b

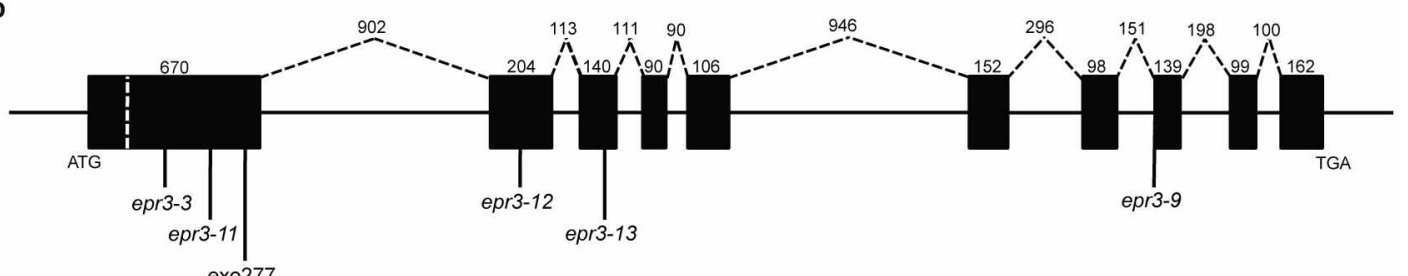

Extended Data Figure $1 \mid$ Genetic mapping and gene structure of Epr3.

9 a, Genetic map ${ }^{57,58}$ around the Epr3 locus. Positions of BAC and TAC clones and of closest markers together with the number of informative recombinations delimiting the Epr3 locus are indicated. b, Alignment of genomic and cDNA sequences defined 10 exons in Epr 3 and a gene structure spanning 4,770 bp. The Epr3 gene is marked together with the exon-intron structure of Epr3 and positions of mutations. 
Lotus Medicago Soybean Tomato

Fragaria Ricinus Sorghum

Lotus Medicago Soybean Tomato Fragaria Ricinus Sorghum

Lotus Medicago Soybean Tomato Fragaria Ricinus Sorghum

Lotus Medicago Soybean Tomato Fragaria Ricinus Sorghum

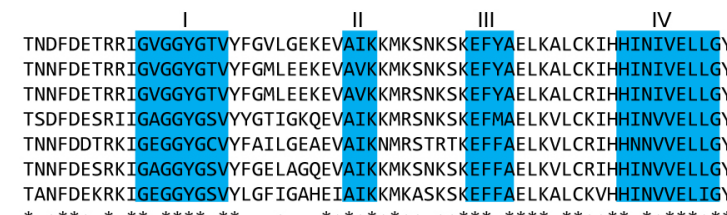

IV $V$
$V$ YASGDDHLYLVYEYVPNGSLSEHLHDPLLKGHQPLSWCARTOIA SAKIEYIHDYTKAQ YASGDDHLYLVYEFVPNGSLCEHLHDPLLKGHOPLSWCARIOIALDAAKGLYYIHDYTKAR Y YASGDDHLYLVYEYVPNGSLNEHLHQPMLKGHKPVLSWTTRTQIAVDTARGIEYIHDHTKSR TYASGEHLCLVYEFVHNGSLNDHLHDPLLKGRQPLSWTARAQIALDTARGIEYIHDHTKTR GYSGDDHLYLVYEYIQNGSLSDHLHDPLLKGYQALSWTARTQIAVDAAKGIEYIHDHTKTR TANFDEKRKIGEGGYGSVYLGFIGAHEIAIKKMKASKSKEFFAELKALCKVHHINVVELIGYAAGDDHLYLVYEYVQNGSLSEHLHDPLLKGHQPLSWTARTQIALDAARGIEYIHDHTKAC

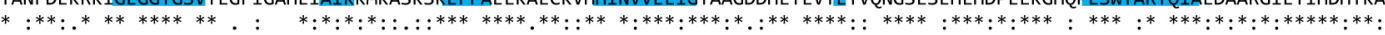

Lotus

Medicago

Soybean

Tomato

Fragaria

Ricinus

Sorghum

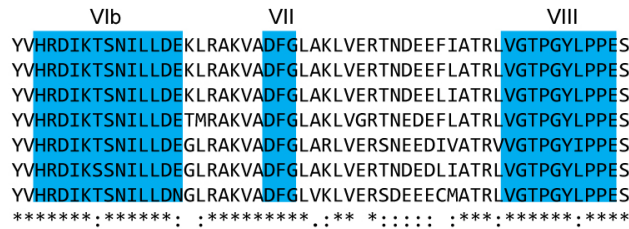

VIII

SLKELQVTVKTDVFAFGVVMLELITGKRALFRDNQEANNMRSLVAVVNQIFQEDNPETALEVTVDGN SVKELQVTIKTDVFAFGVVISELITGKRALFRDNKEANNMKSLIAVVNKIFQDEDPVAALEAVVDGN SVKELQVTIKTDVFAFGVVLAELITGKRALFRDNQEASNMKSLTSVVGQIFKDDDPETVLADAIDGN SVKELOITTKTDVFAFGVVLAELITGKRALIRENGDPNKMKSLISIIHEIFQGEDPDSALESFIDEN SVRELQMTSKSDVYAFGVVLGELITGQRAIIRDNREPKRMRSLVSILYEVFKDDDPEIALKDKIDGN SVKELQVTTKTDVFAFGVVLAELITGQRALVRDNWEPTKTRSLITVVYKIFEDDDPETALENSVDRN SVLELHMTTKSDVYAFGVVLAELITGLRALIRDNKEVNKMKSIISIMRKVFKSENLESSLETIIDPN

$\mathrm{XI}$

Lotus

Medicago

Soybean

Tomato

Fragaria

Ricinus

Sorghum

LORSYPMEDVYNMAELSHWCLRENPVDRPE LRNYPIEGVYKMAELSHWCLSEEPVDRPEMKEIVVAVSKIVMSSIEWEASLGGDSQVFSGVFDGR LQRSYPMEDVYKMAELAHWCLCEDPNVRPEMREIVVALSQIVMSSTEWEASLGGDREVFSGVLDG KGCYPMEDIYKMAEIAEWCLSENAINRPEMREVVVSLSOIRISSTEWEASLGGDSLVFSGVFNG LNGSYPMEEVYKMGEIARWCSSEDPVNRPEMRDIVOSLSHILMSSVEWEASLGGKSEVFSGLFSG LQGSFPVEDVYKMAEIAEWCLNEDPINRPEMRDIVPNLSKIMTSSVEWEASLGGNSTVFSGIYNGR LKDCYPIEEVCKMANVSIWCLSEDPLNRPEMRDIMPTLCQIHLTSIEWEASLGGDGEVFSGVSYGR $:^{*}:^{*}::^{*}::::^{* *} *^{*}: * * *::: \quad::^{*}:^{* * * * * * * * *}{ }^{* * * *}:{ }^{* *}$ 
Extended Data Figure $2 \mid$ Domain structure of EPR3 and homologues proteins. a, Alignment of LysM modules and CxC motifs from EPR3 and plant homologues. The cysteine substituted in epr3-3 and the conserved proline substituted in epr3-10 are marked. Asterisks indicate conserved amino acids. b, Alignment of the full-length EPR3 protein and homologous full-length proteins from Medicago (XP_003613165.1), soybean (XP_003517716.1,

XP_003530632.1), tomato (XP_004242179.1), Ricinus (XP_002527912.1),

Fragaria (XP_004300916.1) and Sorghum (XP_002455766.1). Predicted
$\mathrm{N}$-terminal signal peptides are marked and highlighted in yellow. For EPR3 a signal peptide of 21 amino acids is predicted by SignalP 4.1, assuming that the second of two methionines (arrow) that are eight amino acids apart is the correct $\mathrm{N}$ terminus. The three extracellular LysM domains are marked and highlighted in green. The putative transmembrane region is marked and highlighted in yellow. The classical kinase domains are marked I to XI and highlighted in blue. 
a

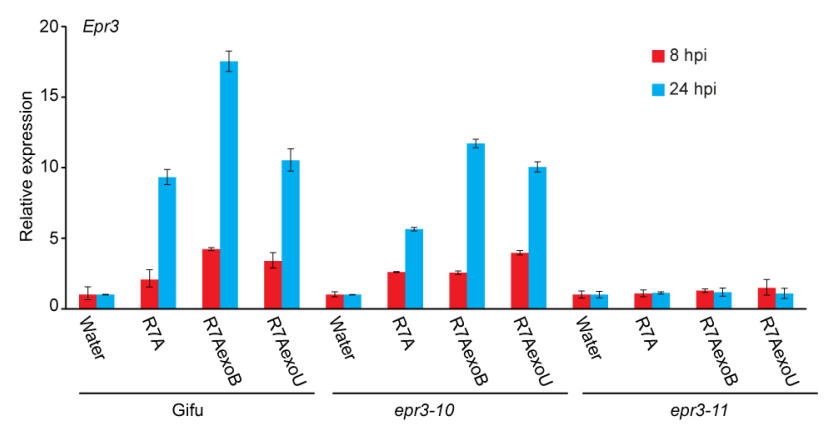

b

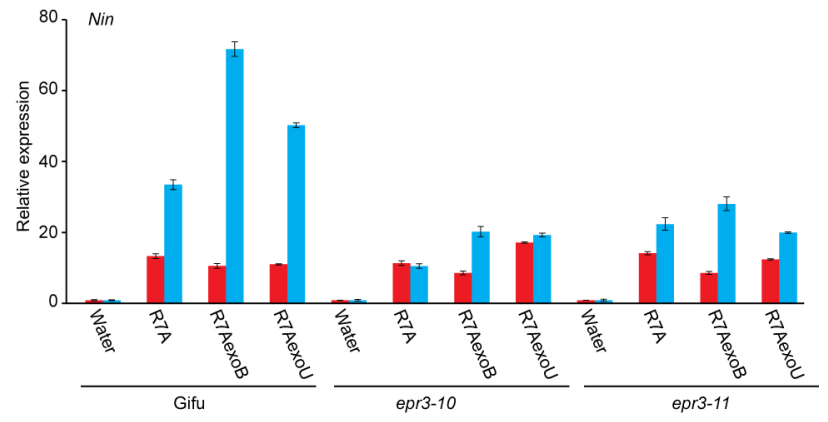

c

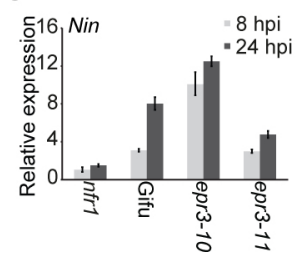

d



e

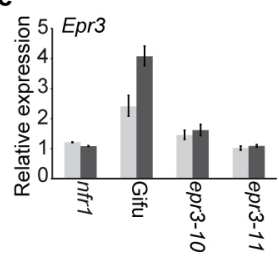

Extended Data Figure $3 \mid$ Quantification of transcript levels. a, b, Relative expression of Epr3 (a) and Nin (b) transcript levels in Gifu, epr3-10 and epr3-11 mutants at 8 and 24 h post inoculation (h.p.i.) with R7A, R7AexoB and R7AexoU. c-e, Relative expression of Nin, Nfyal and Epr3 transcripts in Gifu, epr3-10 and epr3-11 and $n f r 1-1$ roots treated with purified Nod factors. Values are from three biological (each consisting of ten plants) and three technical replicates. Bars show the corresponding upper and lower $95 \%$ confidence intervals. 




d



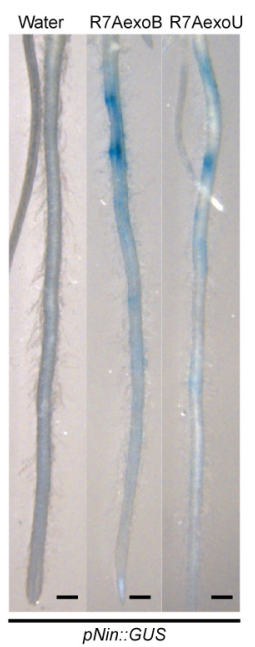

Extended Data Figure $4 \mid$ Localization of EPR3 protein and expression of Epr3. a-c, Membrane localization of EPR3. a, Representative image of EPR3eYFP transiently expressed in N. benthamiana leaves shows co-localization with the plasma membrane dye FM 4-64 shown in b. An overlay is shown in c. d, e, pEpr3::GUS (d) and pNin::GUS (e) expression in roots 14 and 4 days, respectively, after inoculation with R7AexoB and R7AexoU. In d, $n=15$, $n=26$ and $n=10$ for water, R7AexoB and R7AexoU, respectively; in e, $n=10$. Scale bars: a-c, $20 \mu \mathrm{m}$; d, e, $0.5 \mathrm{~mm}$. 




Extended Data Figure $5 \mid$ Phylogeny of the individual LysM modules of all seventeen Lotus LysM receptor kinases. Note that among these receptor

modules do not cluster with the corresponding LysM2 and LysM3 modules of kinases EPR3 stands out as the only protein where both the LysM2 and LysM3 the other receptor kinases. 

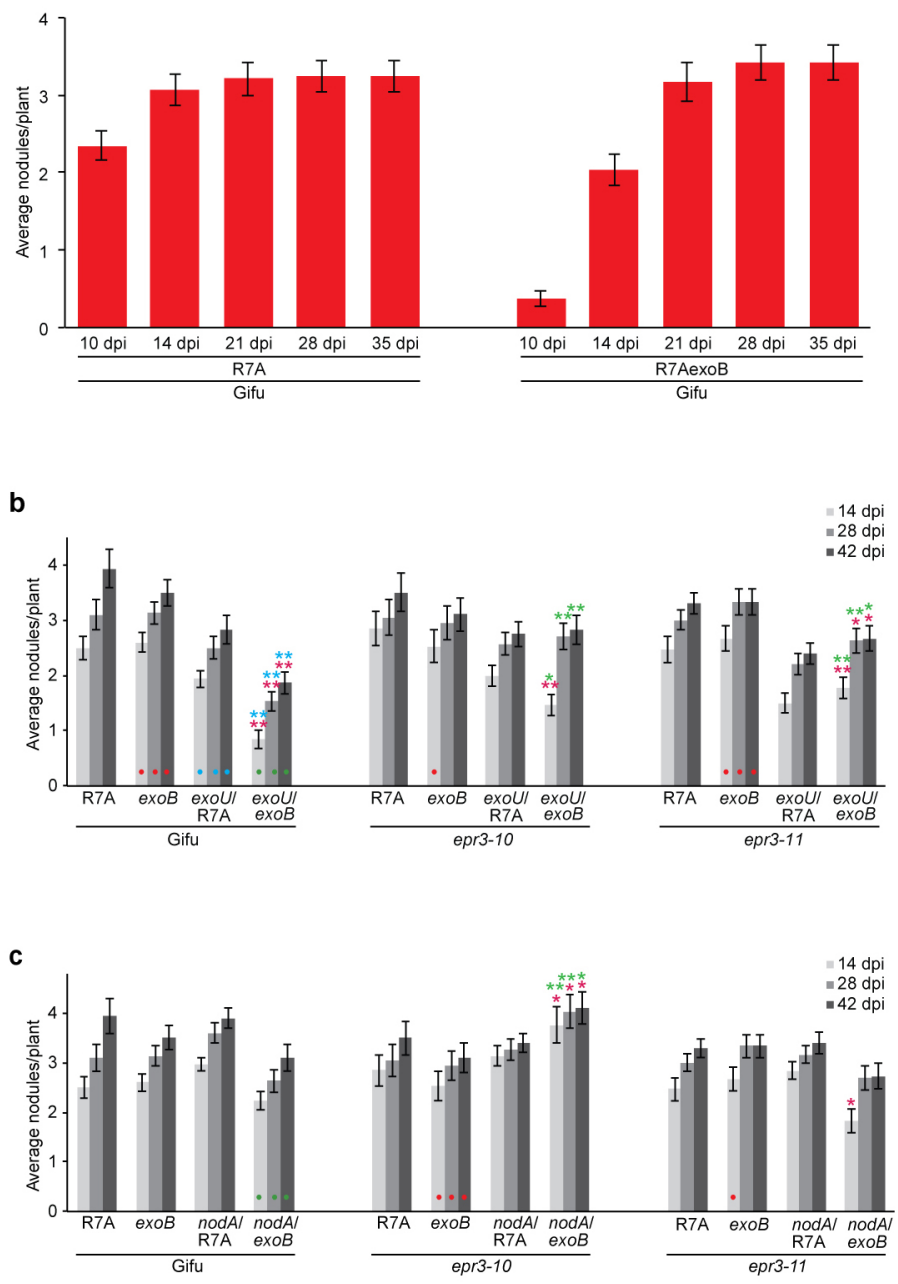

Extended Data Figure $6 \mid$ Competition for infection following R7AexoU pre-inoculation. a, Nodulation kinetics of Gifu inoculated with R7A $(n=30)$ or R7AexoB $(n=29)$. Nodule numbers represent infected nodules only. b. Time course of nodule numbers on Gifu, epr3-10 and epr3-11 inoculated with R7A and R7AexoB or pre-inoculated with R7AexoU followed by inoculation with R7A or R7AexoB $96 \mathrm{~h}$ later. $n=30$, except for epr3-10 R7A $(n=20)$, epr310 R7AexoB $(n=19)$, epr3-10 R7AexoU/R7A $(n=28)$ and epr3-10 R7AexoU/
R7AexoB $(n=28)$. c, Time course of nodule numbers on Gifu, epr3-10 and epr3-11 inoculated with R7A and R7AexoB or pre-inoculated with R7A $\triangle$ nodA followed by inoculation with R7A or R7AexoB $96 \mathrm{~h}$ later. $n=30$, except for epr3-10 R7A $(n=20)$ and epr3-10 R7AnodA/R7AexoB $(n=29)$. ** $P<0.01$ and $* P<0.05$ ( $t$-test) indicate significant differences in nodule number compared to groups at the same d.p.i. and indicated by matching coloured dots. Error bars show s.e.m. 
a Size exclusion column

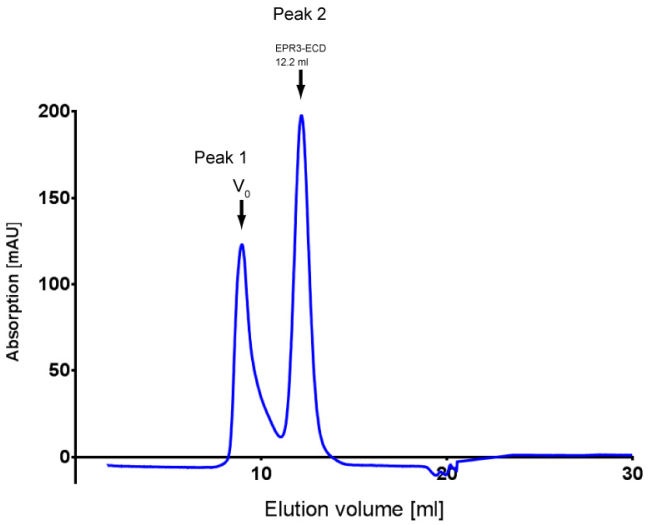

b

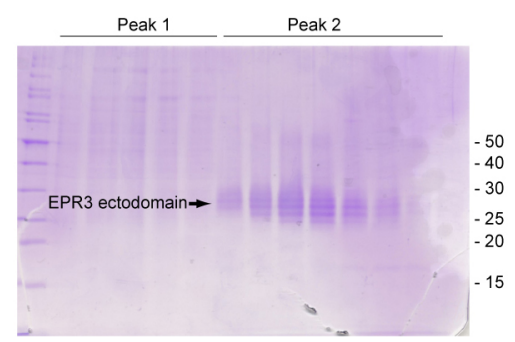

Extended Data Figure $7 \mid$ Purification of the EPR3 ectodomain. a, EPR3 ectodomain expressed in insect cells was purified twice using Ni-IMAC affinity columns followed by a Superdex $7510 / 300$ GL column size exclusion. In the SEC profile shown, pure EPR3 ectodomain elutes as a single peak (Peak 2), at $12.2 \mathrm{ml}$ elution volume. Contaminants elute in the void volume $\left(\mathrm{V}_{0}\right.$; Peak 1$)$.
mAU is UV absorbance at $280 \mathrm{~nm}$. b. Corresponding $15 \%$ Coomassie bluestained SDS-PAGE gel. The EPR3 ectodomain from Peak 2 in different glycosylation states is visible as distinct bands (black arrow). Units on the right hand side list the molecular weight (kilodaltons) of marker proteins in the corresponding position in the first lane to the left. 
ARTICLE RESEARCH

a Size exclusion column

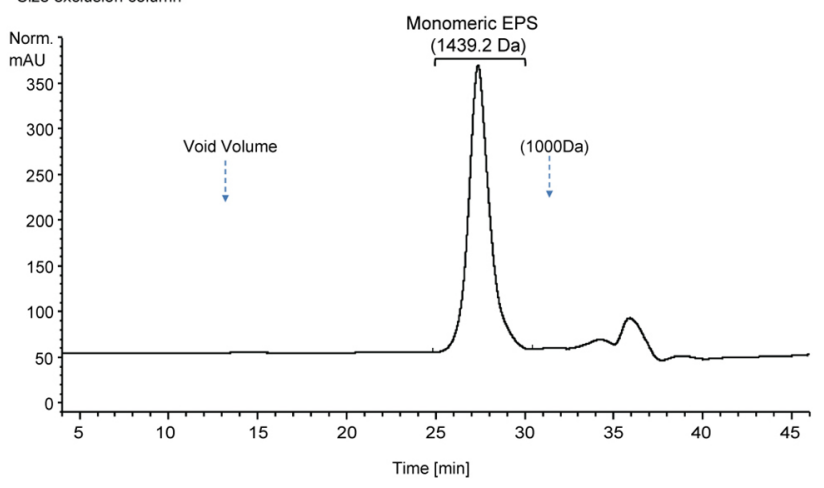

b

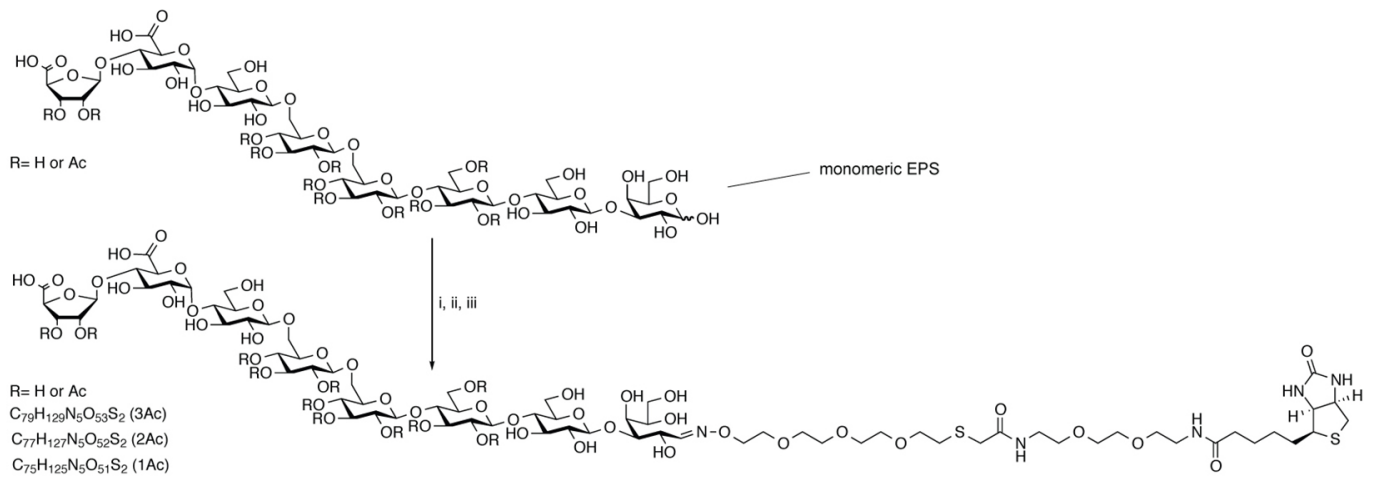

C

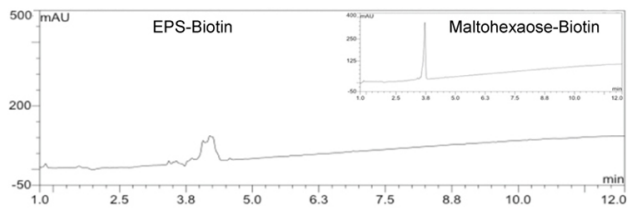

d



e

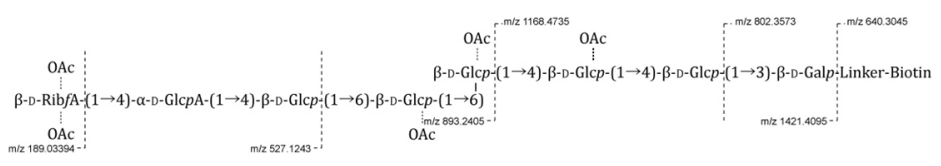


Extended Data Figure $8 \mid$ Isolation and characterization of EPS and the EPS-biotin conjugate by high-performance liquid chromatography and mass spectrometry. a, Size-exclusion chromatography profile of monomeric EPS isolated from culture media of R7A $\Delta \mathrm{ndvB}$. R7A $\Delta \mathrm{ndvB}$ is deprived of a 2-linked cyclic glucan ${ }^{24}$. The size-exclusion chromatography separation resolved one major fraction observed by refractive index detection, and the molecular size of the eluting fraction was assigned based on retention times of authentic standards of polysaccharides and MALDI-TOF mass spectrometry. The MALDI-TOF mass spectrometry analysis of the collected fraction was acquired in negative ionization mode and demonstrated the presence of a major monoisotopic $[\mathrm{M}-\mathrm{H}]^{-}$ion at $\mathrm{m} / z 1,437.39$ (calculated $[\mathrm{M}-\mathrm{H}]^{-}=1,437.4055$, and formula weight $=1,439.19$ ) consistent with a Hex $\mathrm{H}_{5}$ GlcARibA

octasaccharide substituted with three OAc groups. Vertical arrows mark column void volume and retention time of a 1,000 Da standard. b, Synthesis of EPS octaose-biotin conjugate. Conditions: (i) Aminooxy-thiol OEG linker, aniline, acetate buffer, $\mathrm{pH} 4.5,40^{\circ} \mathrm{C}, 16 \mathrm{~h}$; (ii) triethylsilane, trifluoroacetic acid, $15 \mathrm{~min}$; (iii) biotin-iodoacetamide reagent, borate buffer, $\mathrm{pH} 8.3,15 \mathrm{~min}$. c, High-performance liquid chromatography chromatogram at $206 \mathrm{~nm}$. The chromatogram displays several overlapping peaks, owing to a microheterogenous distribution of OAc groups, ranging from 1 to 3 . The inset shows the chromatogram for the maltohexaose-biotin conjugate. d, Fourier transform ion cyclotron resonance (FT-ICR) mass spectrum of EPS octaosebiotin conjugate. Inset displays isotopic distribution of the $[\mathrm{M}+\mathrm{H}, 3 \mathrm{Ac}]^{+}$ion. e, Structure and fragmentation pattern of EPS octaose-biotin conjugate. The displayed $m / z$ values refer to $\mathbf{d}$. 
Extended Data Table 1 | The number of infected nodules and uninfected nodules ('bumps') on wild-type Gifu and epr3 mutants 6 weeks after inoculation with R7AexoU DsRed

\begin{tabular}{lcccc}
\hline Plant genotype & No. of plants & $\begin{array}{c}\text { Total no. of } \\
\text { uninfected nodules }\end{array}$ & $\begin{array}{c}\text { Total no. and \% of } \\
\text { infected nodules }\end{array}$ & $\begin{array}{c}\text { No. and \% of plants forming } \\
\text { infected nodules }\end{array}$ \\
\hline Gifu & 150 & 5909 & $4(0.07 \%)$ & $4(2 \%)$ \\
epr3-3 & 60 & 1844 & $41(2.2 \%)$ & $27(45 \%)$ \\
epr3-9 & 109 & 1982 & $31(1.5 \%)$ & $26(24 \%)$ \\
epr3-10 (exo277) & 100 & 2805 & $61(2.1 \%)$ & $47(47 \%)$ \\
epr3-11 & 181 & 5963 & $65(1.1 \%)$ & $58(32 \%)$ \\
epr3-12 & 40 & 674 & $16(2.3 \%)$ & $12(30 \%)$ \\
epr3-13 & 163 & 4409 & $54(1.2 \%)$ & $43(26 \%)$ \\
\hline
\end{tabular}

* These numbers include both red and large white nodules infected with R7AexoU. 


\section{RESEARCH ARTICLE}

\section{Extended Data Table 2 | Infection of plant mutants.}

a

\begin{tabular}{lccc}
\hline & Total plants & Uninfected nodules & Infected nodules \\
\hline snf1har1 & 50 & 1321 & 0 \\
snf2har1 & 44 & 342 & 1 \\
\hline
\end{tabular}

b

\begin{tabular}{|c|c|c|c|}
\hline Plant Genotype & Construct & of transformed plants & No. of transformants with nodules \\
\hline Wild type & empty vector & 29 & 29 \\
\hline nfr1 & empty vector & 30 & 0 \\
\hline nfr1 & $p 35 S:: N f r 1:: t 35 S$ & 34 & 29 \\
\hline$n f r 5$ & $p 35 S:: N f r 5:: t 35 S$ & 31 & 26 \\
\hline Wild type & p35S::Epr3::t35S & 34 & 33 \\
\hline nfr1 & p35S::Epr3::t35S & 9 & 0 \\
\hline$n f r 5$ & p35S::Epr3::t35S & 22 & 0 \\
\hline nfr1 nfr5 & p35S::Epr3::t35S & 27 & 0 \\
\hline nfr1 & $p N f r 1:: N f r 1$ & 52 & 47 \\
\hline$n f r 1$ & pEpr3::Epr3 & 35 & 0 \\
\hline nfr1 nfr5 & $p N f r 1:: N f r 1 p N f r 5: N f r 5$ & 10 & 6 \\
\hline
\end{tabular}

a, The number of infected nodules on snf 1 har $1^{59-61}$ and snf2har $1^{62}$ double mutants 6 weeks after inoculation with the R7AexoU DsRed strain. b. Complementation studies in nfr $1-1$ or nfr5-2 single mutants and nfr1-1;nfr5-2 double mutants. Epr3, Nfr1, and Nfr5 sequences were expressed from cognate promoters or the $35 \mathrm{~S}$ promoter using a cassette with a $35 \mathrm{~S}$ terminator.

Nature nature14611.3d 20/6/15 08:17:15 